\title{
Responses of fruit flies (Tephritidae: Dacinae) to novel male attractants in north Queensland, Australia, and improved lures for some pest species
}

\author{
Jane E Royer \\ Department of Agriculture, Fisheries and Forestry, Biosecurity Queensland, PO Box 267, Brisbane, Qld 4000, \\ Australia.
}

\begin{abstract}
Male fruit fly attractants, cue-lure and methyl eugenol (ME), have been successfully used for the last 50 years in the monitoring and control of Dacini fruit flies (Bactrocera and Dacus species). However, over 50\% of Dacini are non-responsive to either lure, including some pest species. A new lure, zingerone, has been found to weakly attract cue- and ME-responsive species in Malaysia. In Australia it attracted a weakly cue-responsive minor pest Bactrocera jarvisi (Tryon) and three 'non-responsive' species. Similar compounds were tested in Queensland and attracted cue- and ME-responsive species and two 'non-responsive' species. In this study, 14 novel compounds, including raspberry ketone formate (RKF) (Melolure) and zingerone, were field tested in comparison with cue-lure and ME at 17 sites in north Queensland. The most attractive novel lures were isoeugenol, methyl-isoeugenol, dihydroeugenol and zingerone. Several 'nonresponsive' species responded to the new lures: Bactrocera halfordiae (Tryon), a species of some market access concern, was most attracted to isoeugenol; B. barringtoniae (Tryon), B. bidentata (May) and B. murrayi (Perkins) responded to isoeugenol, methyl-isoeugenol and dihydroeugenol; two new species of Dacus responded to zingerone. Bactrocera kraussi (Hardy), a cue-responsive minor pest in north Queensland, was significantly more attracted to isoeugenol than cue-lure. The cue-responsive $D$. absonifacies (May) and D. secamoneae Drew were significantly more attracted to zingerone than cue-lure. Bactrocera yorkensis Drew \& Hancock, a ME-responsive species was significantly more attracted to isoeugenol, methyl-isoeugenol and dihydroeugenol than ME. The preferential response to RKF or cue-lure was species specific. Six species were significantly more attracted to RKF, including the pests B. tryoni (Froggatt), B. frauenfeldi (Schiner) and minor pest $B$. bryoniae (Tryon); eight species were significantly more attracted to cue-lure including the pest B. neohumeralis (Hardy). These findings have significance in the search for optimal male lures for pest species elsewhere in the world.
\end{abstract}

Key words Bactrocera, Dacus, endemic species, pest, trapping.

\section{INTRODUCTION}

Many species of the genera Bactrocera Macquart and Dacus Fabricius are serious horticultural pests in tropical and subtropical regions. They cause direct damage to fruits and vegetables, can potentially invade new areas through natural dispersal or movement of infested fruits, cause quarantine restrictions in infested areas and require commercial fruits to undergo treatment prior to export (White \& Elson-Harris 1992; IAEA 2003; Drew \& Romig 2013).

Male parapheromone lures, cue-lure and methyl eugenol (ME), have been used successfully for over 50 years in the monitoring and control of tropical fruit flies. However, over $50 \%$ of Bactrocera and Dacus species do not respond to these lures, including several pest species (Drew et al. 1982; Drew 1989; Metcalf 1990; IAEA 2003; Drew \& Romig 2013).

jane.royer@daff.qld.gov.au

2015 State of Queensland

Austral Entomology (C) 2015 Australian Entomological Society
Without a lure, their monitoring and control is difficult. A species will either respond to cue-lure or ME but not both (Drew 1974). For decades, it was generally thought that all Bactrocera and Dacus species may be categorised into three groups based on their response to either cue-lure (over 200 species) or ME (84 species) or their non-response to these lures (286 species) (Drew et al. 1982; Metcalf \& Metcalf 1992; IAEA 2003; Tan et al. 2011).

Apart from the discovery of the species-specific Vertlure (and the structurally similar propyl- $p$-hydroxybenzoate) for D. vertebratus Bezzi in Africa (Hancock 1985a,b) and development of Latilure for B. latifrons (Hendel) (McGovern et al. 1989; McQuate \& Peck 2001; Ishida et al. 2008; Enomoto et al. 2010; Nishida \& Tan 2014), fruit fly attractant research has largely focused on analogues of cue-lure or ME for invasive pests in non-endemic areas, particularly the oriental fruit fly B.dorsalis (Hendel) and melon fly B. cucurbitae (Coquillett) in Hawaii (Beroza \& Green 1963; Metcalf et al. 1975, 1981, 1983, 1986; Mitchell et al. 1985; DeMilo et al. 
1994; Liquido et al. 1998; Oliver et al. 2002; Casana-Giner et al. 2003a,b; Khrimian et al. 2006, 2009; Jang et al. 2007, 2011). However, any lures tested where there is a limited number of invasive species will only provide information on how those particular species respond to those compounds but not on potential responses of other species.

More recently in Malaysia, zingerone was identified as the attractive compound in the flowers of the Bulbophyllum orchids on which fruit flies congregate (Tan \& Nishida 2000, 2007). When field tested in Malaysia zingerone was found to weakly attract several cue- and ME-responsive species (B. albistrigata de Meijere, B. carambolae Drew \& Hancock, B. caudata (Fabricius), B. cucurbitae, B. dorsalis, B. indonesiae Drew \& Hancock, B. tau (Walker) and B. umbrosa (Fabricius)) (Tan \& Nishida 2000, 2007; Tan 2006). In field tests in Australia, zingerone was highly attractive to B. jarvisi (Tryon) (Fay 2011), a minor pest species previously recorded as only very weakly attracted to cue-lure (Drew 1989; Royer \& Hancock 2012). Zingerone also attracted a new species (B. speewahensis Fay \& Hancock), two 'non-responsive' species (B. aglaiae (Hardy) and $B$. aurea (May)), a rare species not known previously from the region ( $B$. nigrovittata Drew), as well as weakly attracting several cue-responsive species (Fay 2011). The discovery of zingerone was a breakthrough in male lure research. It was a compound of similar structure to cue-lure and ME that attracted both cue- and ME-responsive species as well as non-responsive species.

Fay (2010) also field tested 50 commercially available phenylpropanoids and other benzene-ring compounds at one site in north Queensland over several months and found that some attracted cue- and ME-responsive species as well as two 'non-responsive' species. This showed that testing new compounds in areas of high fruit fly endemicity can have unexpected results. The discovery of zingerone as an alternative lure and results of field testing of other novel compounds in Australia has made it apparent that lure response in fruit flies is more complex than the previously held belief that fruit flies either respond to cue-lure or $\mathrm{ME}$ or are non-responsive (Metcalf 1990; Tan \& Nishida 2012).

Dacine attractive phenylpropanoids and phenylbutanoids such as ME and raspberry ketone are known to occur in several plant groups among the monocots and the eudicots (Raghu 2004). There are 450 species of plants from 80 families that contain varying amounts of ME in essential oils from leaves, roots, stems, flowers or whole plant extracts (Tan \& Nishida 2012). In the wild, native male fruit flies actively seek and ingest ME from natural sources (Tan et al. 2002, 2006; Tan 2006). Cue-lure has not been isolated as a natural product but is rapidly hydrolysed to form raspberry ketone (4-( $p$ hydroxyphenyl)-2-butanone). Raspberry ketone was first isolated from Chinese rhubarb Rheum palmatum and later from raspberries and cranberries and was developed as Willison's lure for B. tryoni (Froggatt) in 1959 (Metcalf \& Metcalf 1992). Raspberry ketone is an effective attractant for melon fly but its lower release rate makes cue-lure more efficient for long-range attraction (Metcalf \& Metcalf 1992). Compounds related to ME such as eugenol and isoeugenol also attract flies and occur in a wide range of plants. Eugenol is a component of clove oil, which has been used for the attraction and collection of fruit flies (White 2001).

Male dacine responses to ME and cue-lure are similar: they are strongly attracted to minute amounts which they compulsively feed on with the same behavioural sequences of orientation, searching, attraction, pulsation of mouthparts, compulsive feeding and regurgitation (Metcalf et al. 1981; Metcalf 1990). Such semiochemicals need to be complementary in structure to the antennal receptor site of the male and once absorbed promote receptor depolarisation. The lures must also be sufficiently volatile to attract males from a considerable distance. Mark-recapture studies with B. dorsalis have shown that ME can attract flies from $2.4 \mathrm{~km}$ (Metcalf \& Metcalf 1992).

Cue-lure and ME act as pheromone precursors that play a role in the sexual behaviour of dacine fruit flies (Shelly \& Dewire 1994; Tan \& Nishida 1996; Shelly 2000). Lure attraction is associated with sexual maturity, with males being unresponsive until 2-4 days after eclosion (Metcalf \& Metcalf 1992). Male flies locate a lure source through upwind anemotaxis (Hee \& Tan 1998; Meats \& Hartland 1999), feed on the source and transport the ingested lures to the rectal gland (Hee \& Tan 2006; Wee \& Tan 2007), which is the site of pheromone synthesis in genus Bactrocera (Hee \& Tan 2005). Pheromones are temporarily stored in the rectal glands (Wee \& Tan 2007; Tan et al. 2011) and emitted later to attract conspecific females (Tan \& Nishida 1996; Hee \& Tan 1998). Consumption of ME and raspberry ketone has been shown to significantly improve male mating performance and competitiveness, and increase fecundity and reduce remating receptivity for females (Tan \& Nishida 1996; Shelly 2000; Wee et al. 2007; Kumaran et al. 2013). Cue-lure-fed male $B$. tryoni have also been shown to be more attractive to females (Kumaran et al. 2014).

In this study, four of the most promising compounds tested by Fay (2010) (isoeugenol, methyl-isoeugenol, dihydroeugenol and zingerone) were tested in north Queensland together with cue-lure and ME. Raspberry ketone formate (RKF) was compared with cue-lure. Nine other phenylpropanoids and phenylbutanoids thought to have promise as lures from their similar chemical structure were also tested.

\section{MATERIALS AND METHODS}

Lures were made from dental wick (sourced from Livingstone Int., Rosebury, New South Wales) and dosed at $3 \mathrm{~mL}$ lure to $1 \mathrm{~mL}$ malathion (David Grays Malathion Garden Spray $500 \mathrm{~g} / \mathrm{L}$ maldison). All lures were sourced from Sigma Aldrich, Castle Hill, New South Wales except 4-(3,4dimethoxyphenyl)-2-butanone which had been synthesised for Dr Harry Fay (DAFF) by the Australian National University and was left over from his previous trials. All lures, except two, were in liquid form. Zingerone was crystalline with a melting point of $40^{\circ} \mathrm{C}$ and was microwaved for approximately 1 min to liquefy. Methyl paraben was a powder and was mixed with a dimethyl sulfoxide solution to dissolve to a liquid. Once 
Table 1 Male lure trapping sites in north Queensland

\begin{tabular}{|c|c|c|c|}
\hline & Site & GPS & Habitat type \\
\hline \multirow{9}{*}{$\begin{array}{l}\text { Coastal } \\
\text { Cairns } \\
\text { Region }\end{array}$} & Wangetti Beach & -16.66576145 .57161 & Coastal forest \\
\hline & Machans Beach & -16.86140145 .76039 & Coastal forest \\
\hline & Lake Placid & -16.87043145 .67619 & Rainforest \\
\hline & Edge Hill & -16.90342145 .74727 & Urban \\
\hline & Parramatta Park & -16.91490145 .76540 & Urban \\
\hline & Lake Morris & -16.94171145 .71768 & Rainforest \\
\hline & Redlynch & -16.96219145 .68008 & Rainforest \\
\hline & Garradunga site 1 & -17.45891146 .01907 & Rainforest \\
\hline & Garradunga site 2 & -17.46010146 .01945 & Rainforest \\
\hline \multirow{6}{*}{$\begin{array}{l}\text { Atherton } \\
\text { Tablelands }\end{array}$} & Kuranda & -16.82652145 .65541 & Rainforest \\
\hline & Speewah & -16.85100145 .60421 & $\begin{array}{c}\text { Transition } \\
\text { forest }\end{array}$ \\
\hline & Atherton & -17.25831145 .48510 & $\begin{array}{r}\text { Rainforest } \\
\text { planting }\end{array}$ \\
\hline & Malanda & -17.33941145 .62468 & Rainforest \\
\hline & Mt Hypipamee & $-17.45351 \quad 145.47246$ & Rainforest \\
\hline & Ravenshoe & -17.60891145 .56052 & Rainforest \\
\hline \multirow[t]{2}{*}{$\begin{array}{l}\text { Cape York } \\
\text { Peninsula }\end{array}$} & Lockhart River & -12.79243143 .33411 & $\begin{array}{c}\text { Transition } \\
\text { forest }\end{array}$ \\
\hline & Portland Roads & -12.61562143 .43492 & Rainforest \\
\hline
\end{tabular}

liquid, the lures were applied with a graduated pipette to the dental wick. Lures were placed in Steiner traps hung approximately $1.3 \mathrm{~m}$ from the ground in shady trees that were fruiting or near fruiting trees, and were maintained in the same position. Steiner traps were made by The Men's Shed, Cairns, Queensland. Traps were placed a minimum of five metres apart. Lure-traps were not replicated within each site as each site was considered a replicate. Lures were replaced every 8 weeks. Traps were cleared weekly except over winter when they were cleared fortnightly due to cooler, drier weather and resultant lower trap catches (May to June in the Cairns and Atherton Tablelands region; from June to November in the Lockhart River region). To prevent cross-contamination of lures between traps fresh disposable latex gloves were used to clear each trap with separate trapping kits used for each lure type. Flies were identified under a stereomicroscope using Drew (1989). Sites were chosen to represent a diversity of habitats (rainforest, transition forest between rainforest and sclerophyll, coastal, urban) in the lowlands near Cairns, highlands on the Atherton Tablelands and Lockhart River region on Cape York Peninsula. Sites, lures and trapping duration at each site are shown in Tables 1 and 2. Compounds tested and CAS numbers are shown in Tables 2 and 3.

Statistical analysis: Each weekly trap catch was considered an independent experimental unit. These discrete (count) data were analysed using a generalised linear model (McCullagh \& Nelder 1989) with the Poisson distribution and log link, using GenStat (2013). In this model, the standard errors were associated with, and appropriate for, the fitted means. An overdispersed Poisson model was adopted for the species which displayed this feature. The interaction between 'location', 'month' and 'year' was fitted first (to account for patterns in abundance), followed by 'lure'. Adjusted means were estimated, and significant differences between these were obtained using protected least significant difference (LSD) testing.

\section{RESULTS}

A total of 374402 fruit flies representing 50 species were collected from 3134 trap clearances between March 2012 and May 2014.

See Table 4 for a summary of species trapped using different lures and Table 5 for a summary of mean trap catch for each species with occurrence greater than $1 \%$ in all trap clearances, showing significant differences between species.

\section{'Non-responsive' species responding to new lures}

Bactrocera halfordiae (Tryon) was significantly more attracted to isoeugenol than to dihydroeugenol (mean 25 times greater) and did not respond to any other lure (Table 5).

Bactrocera barringtoniae (Tryon), B. bidentata (May) and B. murrayi (Perkins) all responded to isoeugenol, methylisoeugenol and dihydroeugenol. Bactrocera barringtoniae was significantly more attracted to methyl-isoeugenol than to isoeugenol or dihydroeugenol. Bactrocera bidentata was significantly more attracted to dihydroeugenol and isoeugenol than to methyl-isoeugenol. Bactrocera murrayi was significantly more attracted to methyl-isoeugenol than isoeugenol or dihydroeugenol (Table 5).

\section{Cue- or ME-responsive species that were more responsive to new lures}

Bactrocera kraussi (Hardy), a cue-responsive species, was significantly more attracted to isoeugenol than to cue-lure or RKF (mean several times greater). There was no significant difference between its attraction to cue-lure, RKF and methylisoeugenol. It was also less attracted to dihydroeugenol (Table 5).

Bactrocera yorkensis Drew \& Hancock, a ME-responding species (Drew et al. 1999), did not respond to ME at all during this study but responded to all three of the new lures isoeugenol, methyl-isoeugenol and dihydroeugenol. It was significantly more attracted to methyl-isoeugenol than isoeugenol and dihydroeugenol.

Zingerone was significantly more attractive to two cueresponsive Dacus species than cue-lure or RKF: D. absonifacies (May) and D. secamoneae Drew (Table 5).

\section{Lures, with summary of species attracted}

\section{Eugenol analogues}

Isoeugenol attracted five non-responsive species, seven ME-responsive species and two cue-responsive species. Of these, Bactrocera aberrans, a non-responsive species, was only trapped twice and B. silvicola, a cue-responsive species, was only trapped three times (all single flies) (Table 4). 
政

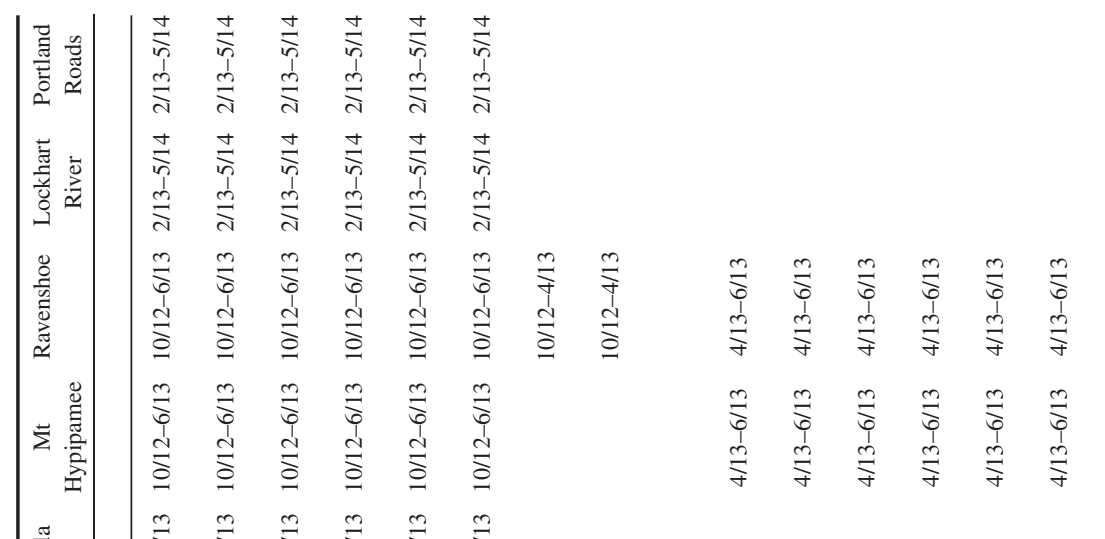

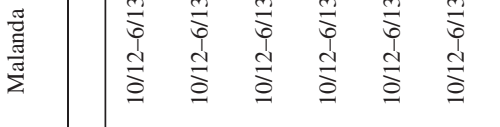

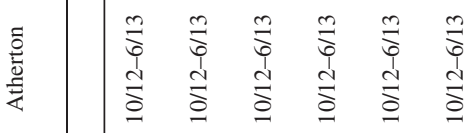

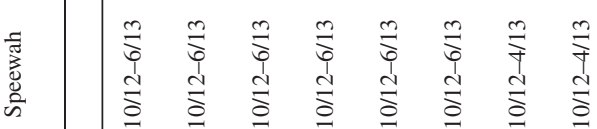

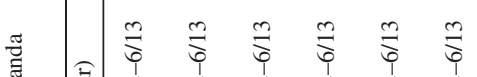

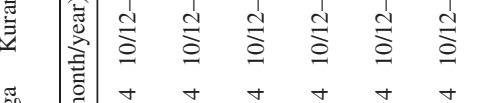

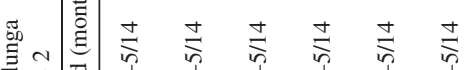

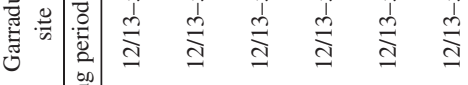

$$
\begin{aligned}
& \text { 密 }
\end{aligned}
$$

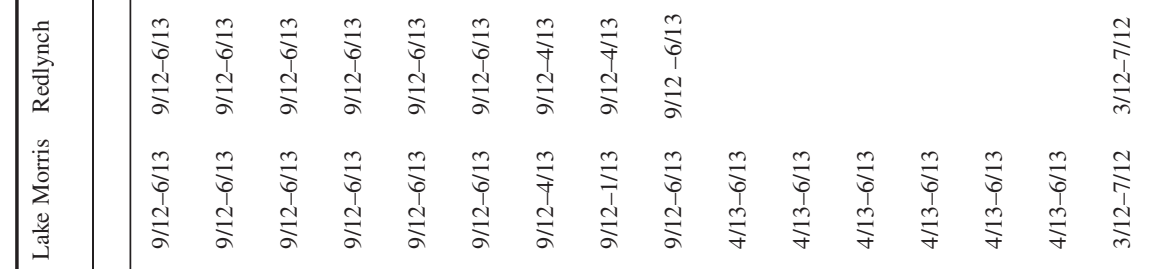

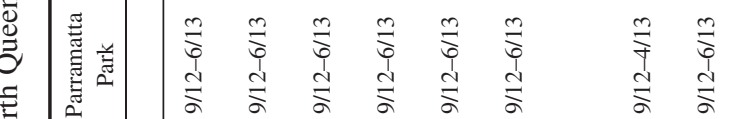

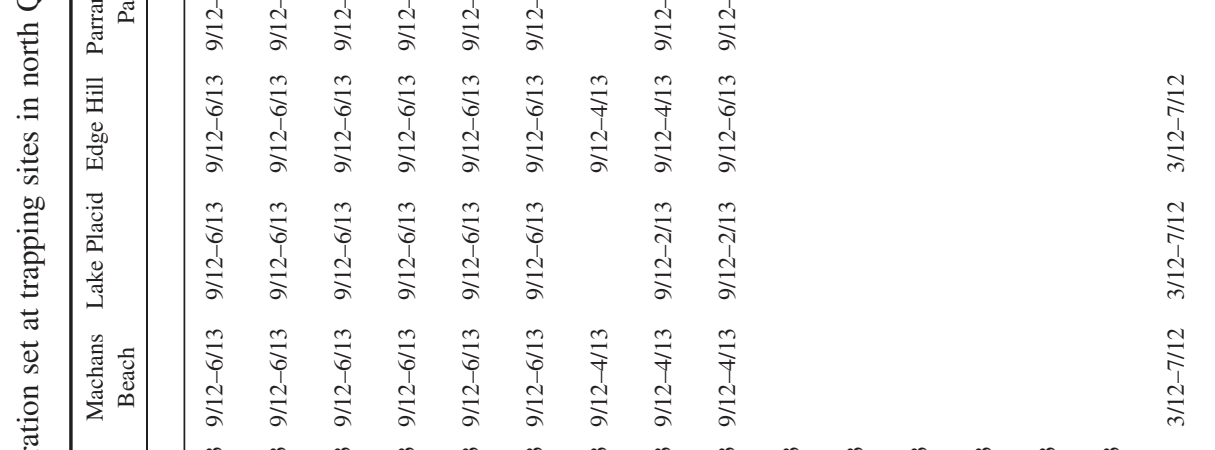

$$
\begin{aligned}
& \text { 莺 }
\end{aligned}
$$

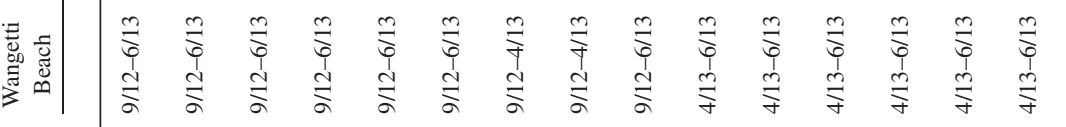

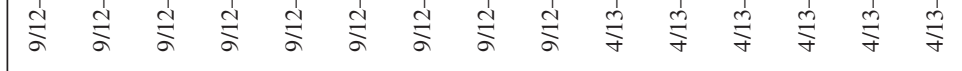

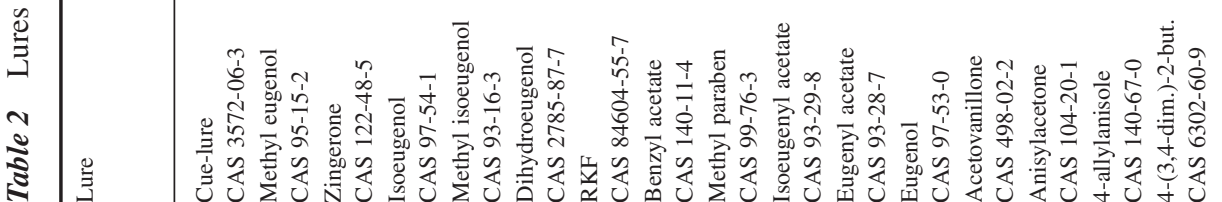




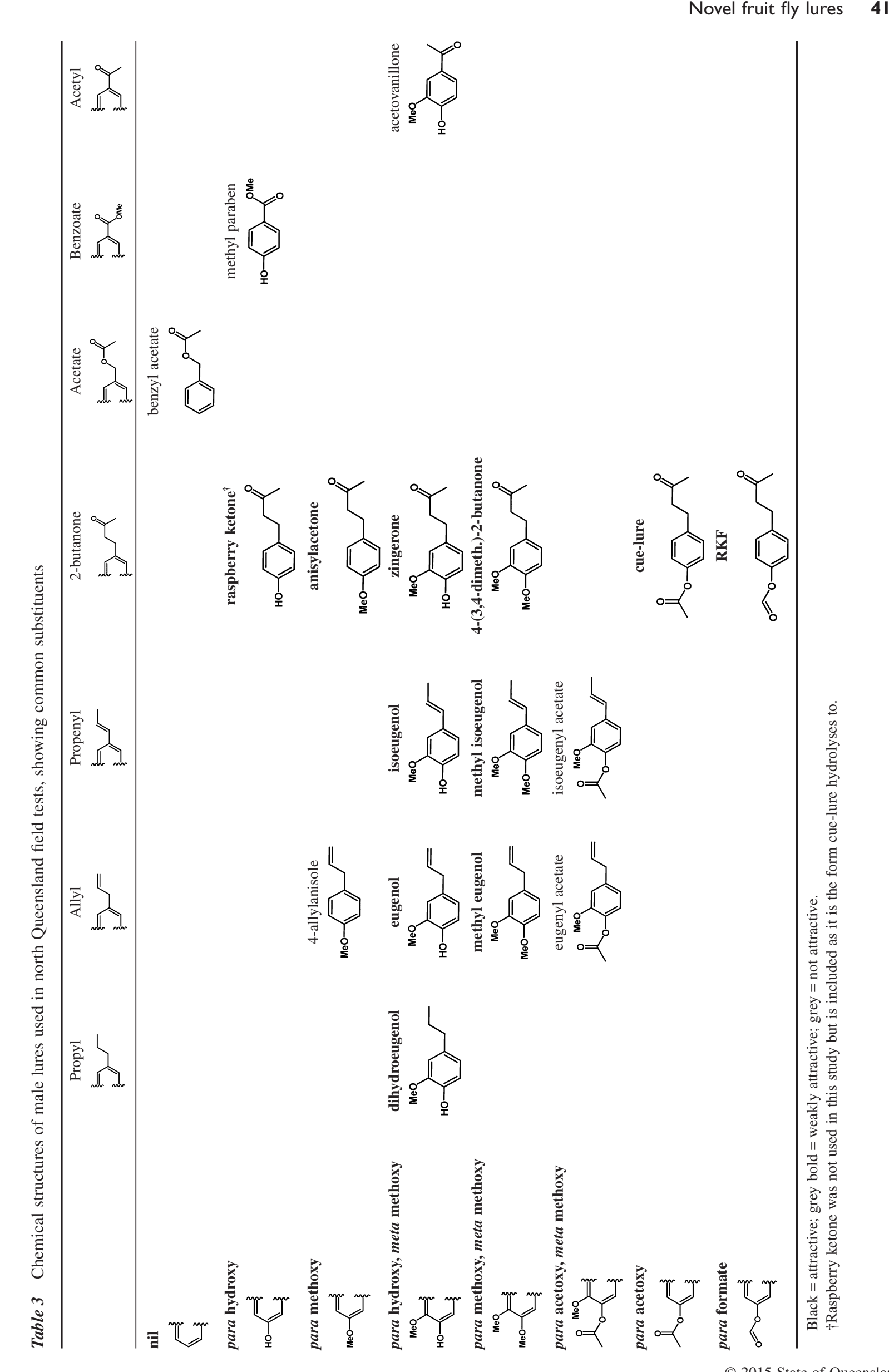


Table 4 Fruit fly species trapped at different lures in north Queensland

\begin{tabular}{|c|c|c|c|c|c|c|c|c|c|c|c|}
\hline & $\begin{array}{c}\text { Lure } \\
\text { response } \\
\text { (cue, ME, } \\
\text { zing, none) }\end{array}$ & $\begin{array}{c}\text { Methyl } \\
\text { isoeugenol }\end{array}$ & Isoeugenol & Dihydroeugenol & Zingerone & Anisylacetone & $\begin{array}{l}\text { 4-(3,4-dimeth.) } \\
\text { - 2-butanone }\end{array}$ & Eugenol & Methyl eugenol & Cue-lure & RKF \\
\hline B. aberrans (Hardy) & none & & 1 & & & & & & & & \\
\hline $\begin{array}{l}\text { B. abscondita (Drew } \\
\text { \& Hancock) }\end{array}$ & cue & & & & & & & & & 3 & 3 \\
\hline $\begin{array}{l}\text { B. aeroginosa (Drew } \\
\text { \& Hancock) }\end{array}$ & cue & & & & 1 & & & & & 3 & 3 \\
\hline B. aglaiae (Hardy) & zing & & & & 3 & & & & & & \\
\hline B. alyxiae (May) & cue & & & & 2 & 1 & & & & 3 & 3 \\
\hline $\begin{array}{l}\text { B. antigone (Drew \& } \\
\text { Hancock) }\end{array}$ & cue & & & & & & & & & 3 & \\
\hline B. aurea (May) & zing & & & & 1 & & & & & & \\
\hline $\begin{array}{l}\text { B. amplexiseta } \\
\text { (May) }\end{array}$ & $\mathrm{ME}$ & & & & & & & & 3 & & \\
\hline B. bancroftii (Tryon) & $\mathrm{ME}^{\mathrm{w}}$ & & & & & & & & 1 & & \\
\hline $\begin{array}{l}\text { B. barringtoniae } \\
\text { (Tryon) }\end{array}$ & none & 3 & 2 & 1 & & & & & & & \\
\hline B. bidentata (May) & none & 2 & 3 & 3 & & & & & & & \\
\hline $\begin{array}{l}\text { B. breviaculeus } \\
\text { (Hardy) }\end{array}$ & cue & & & & 1 & & & & & 3 & 3 \\
\hline B. bryoniae (Tryon) & cue & & & & 1 & & & & & 3 & 3 \\
\hline $\begin{array}{l}\text { B. cacuminata } \\
\text { (Hering) }\end{array}$ & ME & 2 & 1 & 1 & & & & & 3 & & \\
\hline B. chorista (May) & cue & & & & & & & & & 3 & 3 \\
\hline $\begin{array}{l}\text { B. endiandrae } \\
\text { (Perkins \& May) }\end{array}$ & ME & 1 & & & & & & & 3 & & \\
\hline B. fagraea (Tryon) & cue & & & 1 & & & & & & 3 & 3 \\
\hline B. fallacis (Drew) & cue & & & & & & & & & 1 & \\
\hline $\begin{array}{l}\text { B. frauenfeldi } \\
\text { (Schiner) }\end{array}$ & cue & & & & 1 & 2 & 1 & & & 3 & 3 \\
\hline B. halfordiae (Tryon) & none & & 3 & 1 & & & & & & & \\
\hline B. jarvisi (Tryon) & zing & & & & 3 & & & & & 1 & 1 \\
\hline B. kraussi (Hardy) & cue & 2 & 3 & 1 & & & & & & 2 & 2 \\
\hline $\begin{array}{l}\text { B. laticaudus } \\
\text { (Hardy) }\end{array}$ & ME & 1 & 1 & & & & & & 3 & & \\
\hline $\begin{array}{l}\text { B. manskii (Perkins } \\
\text { \& May) }\end{array}$ & cue & & & & & & & & & 3 & 3 \\
\hline B. mayi (Hardy) & ME & 1 & & & & & & & 3 & & \\
\hline $\begin{array}{l}\text { B. melanothoracica } \\
\text { Drew }\end{array}$ & $\mathrm{ME}$ & 1 & 1 & & & & & & 3 & & \\
\hline B. murrayi (Perkins) & none & 3 & 2 & 1 & & & & & & & \\
\hline B. musae (Tryon) & $\mathrm{ME}$ & 2 & 1 & 1 & & & & & 3 & & \\
\hline $\begin{array}{l}\text { B. neohumeralis } \\
\text { (Hardy) }\end{array}$ & cue & & & & 1 & 1 & & & & 3 & 3 \\
\hline $\begin{array}{l}\text { B. pallida (Perkins \& } \\
\text { May) }\end{array}$ & ME & 2 & 1 & 1 & & & & & 3 & & \\
\hline $\begin{array}{l}\text { B. peninsularis } \\
\text { (Drew \& } \\
\text { Hancock) }\end{array}$ & cue & & & & & & & & & 1 & \\
\hline B. quadrata (May) & cue & & & & & & & & & 3 & 3 \\
\hline B. rufescens (May) & cue & & & & & & & & & & 1 \\
\hline $\begin{array}{l}\text { B. russeola (Drew \& } \\
\text { Hancock) }\end{array}$ & cue & & & & & & & & & 1 & \\
\hline B. silvicola (May) & cue & & 1 & 1 & 1 & & & & & 3 & 3 \\
\hline $\begin{array}{l}\text { B. speewahensis Fay } \\
\text { \& Hancock }\end{array}$ & zing & & & & 3 & & & & & & \\
\hline $\begin{array}{l}\text { B. strigifinis } \\
\text { (Walker) }\end{array}$ & cue & & & & & & & & & 3 & 3 \\
\hline B. tigrina (May) & none & & & & 1 & & & & & & 1 \\
\hline B. tryoni (Froggatt) & cue & & & & 1 & & & & & 3 & 3 \\
\hline B. unirufa Drew & ME & 1 & & & & & & & 3 & & \\
\hline B. visenda (Hardy) & $\mathrm{ME}$ & 1 & 1 & 2 & & & & & 3 & & \\
\hline $\begin{array}{l}\text { B. yorkensis Drew \& } \\
\text { Hancock }\end{array}$ & ME & 3 & 2 & 2 & & & & & & & \\
\hline $\begin{array}{l}\text { D. absonifacies } \\
\text { (May) }\end{array}$ & cue & & & & 3 & & & & & 2 & 2 \\
\hline $\begin{array}{l}\text { D. aequalis } \\
\text { Coquillett }\end{array}$ & cue & & & & 2 & & & & & 3 & 3 \\
\hline D. axanus (Hering) & cue & & & & 2 & & & & & 2 & \\
\hline $\begin{array}{l}\text { D. bellulus Drew \& } \\
\text { Hancock }\end{array}$ & cue & & & & 1 & & & & & 3 & 3 \\
\hline D. pusillus (May) & $\mathrm{ME}$ & & & & & & & 1 & 2 & & \\
\hline D. secamoneae Drew & cue & & & & 3 & & & & & 2 & \\
\hline D. sp. nr. pusillus & none & & & & 3 & & & & & & \\
\hline D. sp. nov. & none & & & & 1 & & & & & & \\
\hline
\end{tabular}

$1=$ weak attraction, $2=$ moderate attraction, $3=$ strong attraction, $\mathrm{W}=$ weakly attractive. 


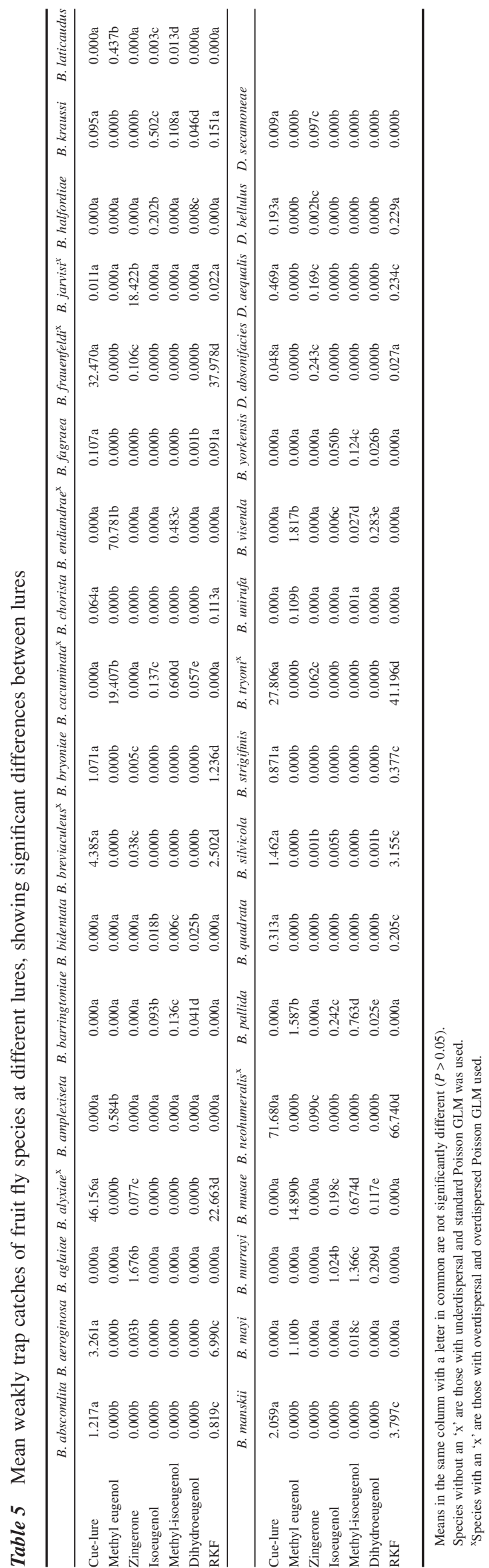

Dihydroeugenol attracted four non-responsive species, five ME-responsive species and three cue-responsive species. This lure was significantly more attractive to B. visenda than isoeugenol and methyl-isoeugenol and was roughly $10 \%$ as attractive as ME to this species (Tables 4 and 5).

Methyl-isoeugenol attracted three non-responsive species, 10 ME-responsive species and one cue-responsive species. Of the ME-responsive species, only a single $B$. melanothoracica and two single $B$. mayi and $B$. unirufa were trapped. This lure was significantly more attractive to the ME-responsive B. cacuminata, B. laticaudus, B. musae, B. pallida and $B$. yorkensis than isoeugenol or dihydroeugenol and was nearly half as attractive as ME to B. pallida (Tables 4 and 5).

\section{Zingerone}

Zingerone attracted three non-responsive species (including a single B. tigrina and the new D. sp. nr. pusillus and D. sp. nov.), four zingerone-responsive species and 13 cueresponsive species. Of the cue-responsive species, only a single $B$. silvicola and two single $B$. aeroginos $a$ were trapped (Table 4). The new undescribed species closely related to the ME-responsive D. pusillus (May) was trapped in the Lockhart River region on 31 occasions, sometimes in high numbers (e.g. 63 flies in one trap clearance) with a total of 259 flies trapped. A single fly of another new undescribed species of Dacus was also collected at Lockhart River in November 2013. These species will be described in another paper (JE Royer \& DL Hancock unpubl. data 2014).

\section{Cue-lure and RKF}

At the sites where both cue-lure and RKF were set, 25 species were trapped at cue-lure and 22 at RKF (see Table 4, though note that there are 26 species listed for cue-lure as this lure only was set at Lockhart where B. antigone occurs). For species with occurrence less than $1 \%$ in the traps, pairwise tests between means using LSD were not able to be calculated.

Six species were significantly more attracted to RKF than to cue-lure: B. aeroginosa, B. bryoniae, B. frauenfeldi, B. manskii (Perkins \& May), B. silvicola and B. tryoni (Table 5). Approximately two thirds more B. tryoni were trapped at RKF than cue-lure. Species trapped at RKF but not at cue-lure were single flies of B. rufescens (May) and the non-responsive B. tigrina (Table 4).

Eight species were significantly more attracted to cue-lure than RKF: B. abscondita (Drew \& Hancock), B. alyxiae, B. breviaculeus, B. neohumeralis, B. quadrata (May), B. strigifinis (Walker), D. aequalis and D. secamoneae (Table 5). Species trapped at cue-lure but not at RKF were: B. fallacis (Drew), a rarer species, single flies trapped three times; B. peninsularis (Drew \& Hancock), a Cape York species at the southern end of its distribution, single fly trapped once; B. russeola (Drew \& Hancock), nine flies trapped once; D. axanus (Hering), two single flies; and D. secamoneae, trapped on three occasions (Table 4).

Six species, B. chorista (May), B. fagraea, B. jarvisi, B. kraussi, D. absonifacies and D. bellulus, showed no 
significant difference between their attraction to cue-lure and RKF. These species were all trapped in low numbers.

\section{Weakly attractive lures}

Anisylacetone (4-(4 methoxyphenol)-2 butanone) was weakly attractive to three cue-responsive flies. Out of nine trap clearances, it caught 2 B. alyxiae, 34 B. frauenfeldi and 6 B. neohumeralis.

4-(3,4-dimethoxyphenyl)-2-butanone trapped only $B$. frauenfeld $i$ with an average weekly trap catch of 0.2 flies. The traps that did catch B. frauenfeldi usually only caught one or two flies per clearance.

Eugenol trapped a single D. pusillus at Lake Morris.

\section{Non-attractive lures}

Methyl paraben (Vertlure), eugenyl acetate, isoeugenyl acetate, 4-allylanisole (estragole or methyl chavicol) and acetovanillone trapped no fruit flies. Fay (2010) had also tested the latter and did not report any flies caught. Benzyl acetate trapped only a few Platystomatidae (Tephritoidea).

\section{New distributions recorded by new lures}

Bactrocera aglaiae was newly recorded from Lockhart River and Portland Roads. It was previously recorded from the Mossman to Tully districts (Hancock et al. 2000). This species was collected at zingerone.

Bactrocera aurea was newly recorded from Lockhart River. It was previously known from southeast Queensland (Hancock et al. 2000). This species was trapped using zingerone.

Bactrocera bidentata was newly recorded from Lockhart River and was previously known from the Cairns, Innisfail and Rockhampton districts (Hancock et al. 2000; Royer \& Hancock 2012). This species was trapped using isoeugenol, methyl-isoeugenol and dihydroeugenol.

Bactrocera halfordiae was newly recorded at Cairns, Atherton, Mt Hypipamee, Malanda and Ravenshoe. It was previously recorded from Rockhampton to the Sydney district (Hancock et al. 2000). This species was trapped using isoeugenol and dihydroeugenol.

Bactrocera speewahensis was newly recorded in Cairns, Machans Beach, Yorkeys Knob, Wangetti Beach, Lockhart River and Portland Roads. Although traps were set near Speewah where the original specimens were found, no specimens were collected there or elsewhere on the Atherton Tablelands. It was previously recorded from the Kuranda district near Cairns (Huxham et al. 2006). This species was trapped using zingerone.

Dacus absonifacies was newly recorded from Ravenshoe and Mt Hypipamee on the Atherton Tablelands. It was previously known from southeast Queensland to central New South Wales and the Australian Capital Territory (Hancock et al. 2000). This species was trapped using cue-lure, RKF and zingerone.

Dacus secamoneae was newly recorded from Cairns, Wangetti Beach, Kuranda, Atherton, Mt Hypipamee,
Ravenshoe, Lockhart River and Portland Roads. It was previously known from the Northern Territory, Umagico (Cape York) and Chillagoe in northern Queensland (Huxham \& Hancock 2002). This species was trapped using cue-lure and zingerone.

Representative specimens are deposited in the Queensland Department of Agriculture, Fisheries and Forestry (formerly Queensland Department of Primary Industries) insect collection in Brisbane.

\section{DISCUSSION}

\section{Species response to lures}

Non-responsive species responding to the new lures

Several Bactrocera species including B.halfordiae, $B$. barringtoniae and $B$. bidentata had previously been reported as non-responsive to male fruit fly attractants (Drew 1989; Hancock et al. 2000). However, the data presented here are the first records of $B$. halfordiae, B. barringtoniae and $B$. bidentata regularly responding to male lures and $B$. murrayi responding to methyl-isoeugenol and dihydroeugenol. Fay (2010) recorded B. murrayi at isoeugenol only but in this study it was attracted more to methyl-isoeugenol than isoeugenol.

Bactrocera halfordiae responded strongly to isoeugenol and weakly to dihydroeugenol. These lures were also tested in southeast Queensland between September and November 2014 in rainforest where Planchonella australis (Sapotaceae), the preferred host of $B$. halfordiae, was common. Over an 8-week period, this species was regularly trapped, with an average weekly catch per trap of 48 flies at isoeugenol and two at dihydroeugenol. Bactrocera halfordiae is in the B. fagraea complex along with $B$. kraussi, a cue-responsive minor pest that was also significantly more attracted to isoeugenol than any other lure. It is noteworthy that these closely related species responded most strongly to the same lure.

Bactrocera halfordiae was recently considered a possible market access pest due to old host records from citrus (May 1953 in Hancock et al. 2000). However, since then, the only host records have been in rainforest fruit (Hancock et al. 2000). A lure for $B$. halfordiae has importance if there is ever a requirement to monitor populations to demonstrate 'pest freedom' for market access.

Bactrocera barringtoniae, B. bidentata and B. murrayi all responded to isoeugenol, methyl-isoeugenol and dihydroeugenol to varying degrees and were not recorded at any of the other lures. These three lures all have alkoxy substituents at the para and meta positions and a three carbon primary side chain (Table 3). These three flies are in subgenus Bactrocera (Bactrocera) but are not in the same species complex. Fay (2010) tested these three lures in north Queensland but only recorded $B$. murrayi as moderately attracted to isoeugenol and not to the other two lures. However, in that study, the lures were only tested at one site at Speewah in north Queensland for 6 months. Speewah is in a transition zone between rainforest and sclerophyll and there might have been 
an absence of the rainforest hosts for B. barringtoniae and B. bidentata.

Bactrocera barringtoniae was significantly more attracted to methyl-isoeugenol. It responded less strongly to isoeugenol (which also has a propenyl primary side chain) and dihydroeugenol (saturated propyl primary side chain), but did not respond to ME (allyl primary side chain with a different unsaturation point to isoeugenol). Methyl-isoeugenol has methoxy at the para and meta positions while isoeugenol and dihydroeugenol have a vanillyl group (hydroxy para and methoxy meta). It appears that the combination of the propenyl primary substituent and methoxy at the para and meta positions is the best lure receptor fit for this species.

Specimens identified as B. barringtoniae (including those listed as 'B. sp. nr. barringtoniae' by Royer \& Hancock 2012) have been recorded sporadically from ME traps from Portland Roads in northern Cape York Peninsula to Coen, Cedar Bay, Port Douglas and the Cairns region between 1996 and 2011 (JE Royer unpubl. data 2014). ME and methyl-isoeugenol differ only in the placement of the double bond on the primary side chain (Table 3). Bactrocera barringtoniae was initially recorded as responsive to cue-lure (Drew 1989); however, this was later amended to having no lure response (Drew et al. 1999). One further specimen listed under ' $B$. sp. nr. barringtoniae' by Royer and Hancock (2012) was trapped at cue-lure in Coen in 2010 but this appears to be morphologically distinct.

As $B$. barringtoniae is most attracted to methyl-isoeugenol, the occasional records of this species at the structurally similar $\mathrm{ME}$ are not surprising. Bactrocera barringtoniae responded to three lures in this study, so perhaps it is weakly responsive to more lures such as ME but does not respond until sexually mature. This was found to be the case with anisylacetone, which did not attract $B$. cucurbitae until after they attain sexual maturity at 7-11 days after emergence from pupation (Beroza et al. 1960), and was later found to be a weak attractant relative to cue-lure (Beroza \& Green 1963).

Bactrocera barringtoniae was not placed in a species complex by Drew (1989) but a morphologically similar species, B. parabarringtoniae Drew \& Hancock, was described subsequently from the Torres Strait, collected in ME traps (Drew et al. 1999). The host of B. barringtoniae is Barringtonia calyptrata (mango pine) (family Lecythidaceae), while that of B. parabarringtoniae is the closely related Barringtonia racemosa. This gives an interesting clue to the evolution of lure response, with two closely related species, from contiguous geographic areas and with hosts in the same genus, responding to similar lures: the $B$. barringtoniae preferred lure, methyl-isoeugenol, only differing from the B. parabarringtoniae lure, $\mathrm{ME}$, in the placement of the double bond on the primary substituent.

Bactrocera bidentata was significantly more attracted to isoeugenol and dihydroeugenol than methyl-isoeugenol. Both of these compounds have a vanillyl group in combination with a propenyl (isoeugenol) or propyl (dihydroeugenol) primary substituent (Table 3). While B. bidentata also responded to methyl-isoeugenol, it does not respond to the chemically similar ME (Drew 1989; JE Royer unpubl. data 2014). However, there are two occasions where single flies have been collected in ME traps (Royer \& Hancock 2012).

Bactrocera bidentata did not respond to zingerone, another compound with a vanillyl group in combination with the longer oxygenated 2-butanone primary side chain. The combination of a vanillyl group and a three-carbon primary side chain that is either saturated (propyl) or has the double bond in the second position (propenyl) appears to be the best lure for this species.

Bactrocera bidentata is currently placed in the B. bidentata complex with B. aeroginosa (Drew 1989). It is known from only one host, Carallia brachiata (family Rhizophoraceae). Bactrocera aeroginosa responded only to cue-lure and RKF and very weakly to zingerone in this study, so there was no overlap in lure response between these two species. However, B. aeroginosa breeds in a very different host (Pycnarrhena novoguineensis, family Menispermaceae) (Hancock et al. 2000) and the presumed relationship of these two species is possibly artificial.

Bactrocera murrayi responded most strongly to methylisoeugenol, then isoeugenol and dihydroeugenol. This species does not respond to ME (Drew 1989; JE Royer unpubl. data 2014), although the apparently closely related species B. decurtans (May) does. Both these species are morphologically similar and they have been somewhat paired as taxonomic anomalies. They were previously included in subgenus Bactrocera (Polistomimetes), partly on the basis of an absence of prescutellar and supra-alar bristles. However, they differ from typical members of subgenus Polistomimetes (now regarded as a synonym of subgenus Tetradacus) by not having an elongate-oval abdomen, and are likely to be aberrant members of subgenus Bactrocera (as suggested by Drew 1989 and placed by Hancock 2013).

Bactrocera murrayi and B. decurtans are taxonomically closely related species, with similar morphology and overlapping geographic ranges. Although they have different host ranges, both species are attracted to structurally similar lures (ME in the case of $B$. decurtans and methyl-isoeugenol in the case of B. murrayi) which may provide an indication of the evolution of their lure response.

\section{ME-responsive Bactrocera yorkensis stronger response to new lures}

Bactrocera yorkensis was most attracted to methyl-isoeugenol and then to isoeugenol and dihydroeugenol. It is known as a ME-responsive species (Drew et al. 1999) but was not trapped at all using ME during this study. Its order of lure preference therefore appears to be methyl-isoeugenol > isoeugenol and dihydroeugenol $>\mathrm{ME}$. The stronger response to all three new lures over ME seems to demonstrate the importance of the double bond being in the second position in the primary side chain, or the side chain being saturated.

This species was trapped in low numbers from various locations in north Queensland (Drew et al. 1999) during the intensive ME trapping of the Papaya Fruit Fly Eradication Program. 
As it has only been infrequently trapped since then (occasionally at Bamaga, Weipa and Cooktown and most years in Lockhart River) (JE Royer unpubl. data 2014), there has been some conjecture that the intensive trapping may have eradicated the species from the Cairns region. However, in the present study, it has been recorded at the Cairns rainforest suburbs of Redlynch, Lake Placid and Lake Morris and most frequently from Wangetti Beach north of Cairns and Lockhart River.

Bactrocera yorkensis is a small species, unique in appearance, with a yellow band connecting the postpronotal lobe and notopleural callus. It is included in subgenus Bactrocera (Bactrocera) and its host is not known.

In summary, presence and placement of the double bond on the three carbon primary side chain is important to species attraction. Bactrocera barringtoniae, B. bidentata and $B$. murrayi only responded when this was either between the first and second carbon (propenyl) or when the carbon chain was saturated (propyl), whereas B. yorkensis additionally responds to ME (Drew et al. 1999) with the double bond between the second and third carbon (allyl). For these four species, a three-carbon primary side chain in combination with a dimethoxy or vanillyl group at the para and meta positions is the best lure.

Metcalf and Metcalf (1992) noted that B. dorsalis receptors can detect the presence and position of the $\mathrm{C}=\mathrm{C}$ double bond on the primary substituent, as this species had a much lower limit of response for ME (0.001-0.01) than methyl-isoeugenol (0.03) in laboratory trials. The influence of the unsaturated propyl primary substituent was also evident in feeding behaviour of B. dorsalis which fed compulsively on ME but was attracted to and fed on saturated 3,4-dimethoxybenzenes but much less compulsively (Metcalf \& Metcalf 1992).

\section{Cue-responsive Bactrocera kraussi response to isoeugenol}

Bactrocera kraussi responded most strongly to isoeugenol and there was no significant difference in its attraction to cue-lure, RKF and methyl-isoeugenol. It also responded more weakly to dihydroeugenol. This wide range of response to structurally relatively dissimilar compounds is interesting (Table 3). It was the only cue-group responsive species to respond to the eugenol analogues apart from B. silvicola, which was only recorded on three occasions at isoeugenol and once at dihydroeugenol. Although B. kraussi has a wide host range and is considered a minor pest, it is relatively rare in cue-lure trap catches (JE Royer unpubl. data 2014). The data presented here indicates that this is due to a weak cue-lure attraction. This species is of some economic concern as it has been recorded from banana, citrus, guava, mango and peach (Hancock et al. 2000). Having a stronger attractant for it would be useful for horticultural production areas wishing to demonstrate pest freedom.

\section{Cue-responsive $\mathrm{D}$. absonifacies and $\mathrm{D}$. secamoneae response to zingerone}

Dacus absonifacies and D. secamoneae were significantly more attracted to zingerone than to cue-lure or RKF. These three compounds have 2-butanone as the primary side chain. However, zingerone has a vanillyl group in the para and meta positions, compared with substituents in the para position only: an acetoxy in the case of cue-lure and a formate in the case of RKF. Several Dacus species responded to both zingerone and the cue-group with some species responding more strongly to one or the other. No Dacus or any other flies responded to methyl paraben (Vertlure) in this study, a lure attractive to D. vertebratus in Africa.

\section{Lures}

\section{Comparison of RKF with cue-lure}

The preferential response to RKF or cue-lure was species specific. Six species were significantly more attracted to RKF than cue-lure, eight species were significantly more attracted to cue-lure than RKF, and for six species, there was no significant difference in their attraction to the two lures (Table 5). Three species of some economic concern were more responsive to RKF: B.tryoni, Queensland fruit fly, a highly polyphagous pest distributed throughout most of Queensland and also in parts of New South Wales, Victoria and the Northern Territory (Hancock et al. 2000; Royer \& Hancock 2012); B. frauenfeldi, an invasive polyphagous pest in north Queensland that has spread as far as Townsville but has not moved further south (JE Royer et al. unpubl. data 2012); and B. bryoniae, a minor pest recorded from capsicum and chilli and known from northern Western Australia, Northern Territory and eastern Australia as far south as Sydney, New South Wales (Hancock et al. 2000). The only economically important species with a significantly stronger response to cue-lure than RKF was B. neohumeralis (lesser Queensland fruit fly). Data from this study indicate that monitoring and control of B. tryoni, B. frauenfeldi and B. bryoniae may be improved with the use of RKF instead of cue-lure, particularly for B. tryoni where the trapping mean with RKF was two thirds greater than that of cue-lure. Conversely, for B. neohumeralis, cue-lure is the superior lure. However, caution should be used in assuming that these lures would behave the same way in dry temperate areas as seen here in humid tropical environments due to potential differences in rate of hydrolysis. Confirmatory studies in subtropical/temperate regions could be conducted to determine if the differences in attraction found here apply in all climatic environments.

Metcalf and Metcalf (1992) reported RKF to be twice as attractive to $B$. cucurbitae in 2 day tests and it was later reassessed in Hawaii and was found to be 1.5 to 2 times more attractive to wild B. cucurbitae in Hawaii than cue-lure (Casana-Giner et al. 2003b; Jang et al. 2007). However, the data presented herein indicate that this stronger response to RKF cannot be generalised for all cue-responding species. Given the higher rate of attraction of the pest B. tryoni to RKF, it would be worthwhile field testing this lure in comparison with cue-lure species in other parts of the world to determine whether RKF is an improved attractant for other cueresponding pests. 


\section{Response to isoeugenol, methyl-isoeugenol and dihydroeugenol}

These three eugenol analogues had a similar effect - they all attracted the 'non-responsive' $B$. barringtoniae, B. bidentata and $B$. murrayi and were all more attractive to B. yorkensis than ME. These species, except B. bidentata, were most attracted to methyl-isoeugenol, followed by isoeugenol and then dihydroeugenol. The lures also all attracted some ME-responsive species, with methyl-isoeugenol most similar to $\mathrm{ME}$ in range and numbers of ME-responsive species attracted. They are all structurally similar to ME in having alkoxy substituents meta and para and a three-carbon primary side chain.

These lures were also tested in early 2012 for attractiveness to $B$. calophylli, a non-responsive species currently (but erroneously: DL Hancock unpubl. data 2014) placed in subgenus B. (Gymnodacus). Traps were set at the Parramatta Park site, which had many fruiting Calophyllum inophyllum trees, the host of this species. While many B. calophylli were trapped in a Cera Trap® at this site, only a single specimen was caught at methyl-isoeugenol, presumably accidentally.

These three lures have been tested previously by fruit fly researchers dating back to the first record of any fruit fly response to a lure by Howlett (1912), when he observed three species of Bactrocera attracted to citronella oil. Howlett (1915) identified ME as the attractive compound and also field tested a number of other compounds in citronella including isoeugenol. He found that $B$. diversa (Coquillett) was strongly attracted to isoeugenol, B. zonata (Saunders) to $\mathrm{ME}$, and $B$. dorsalis to both $\mathrm{ME}$ and isoeugenol; he also found that methyl-isoeugenol ('methylate of isoeugenol') attracted all three species. Howlett noted that $B$. diversa was not attracted at all to ME; however, this species is now known to be weakly ME responsive (Drew \& Romig 2013) and its strong attraction to isoeugenol appears to have been largely forgotten. This may be due to the lack of economic importance of $B$. diversa and therefore a lack of interest in its lure.

Steiner (1952) field tested ME, isoeugenol and methylisoeugenol as attractants for $B$. dorsalis when it first invaded Hawaii. While it is well known that ME was found to be a strong attractant for this species, he also found that methylisoeugenol and isoeugenol were effective attractants for $B$. dorsalis, although much less effective than ME. Methylisoeugenol was roughly $35 \%$ as attractive as $\mathrm{ME}$ and isoeugenol was $13 \%$ as attractive. This higher attraction of methyl-isoeugenol to an ME-responsive fly confirms the findings in this study for several ME-responsive species and similar findings in Papua New Guinea (PNG) (JE Royer et al. unpubl. data 2014). Beroza and Green (1963) cage tested isoeugenol and methyl-isoeugenol and found them both attractive to B.dorsalis. DeMilo et al. (1994) field tested methyl-isoeugenol (Veratrole 5) against $B$. dorsalis and found it to have some attraction and reasonable persistency. He also noted that isoeugenol, dihydroeugenol and eugenol were poorly attractive, but out of these isoeugenol was the most attractive.
Flath et al. (1994) tested several hundred compounds as attractants for $B$. latifrons, which led to the discovery of alphaionol/ionone as an attractant. One of the more promising compounds tested was isoeugenol which was approximately $25 \%$ as attractive to B. latifrons as alpha-ionone. Later McQuate and Peck (2001) identified cade oil as an effective synergist for alpha-ionol. The attractive compounds in cade oil were isolated by McQuate et al. (2004), and isoeugenol, dihydroeugenol and eugenol were found to be equally effective synergists under field conditions, with eugenol chosen for further tests for safety and cost reasons. They noted that the similarity in structures of the synergistic compounds showed that there was a response to a core 2-methoxyphenol structure, with fly response little affected by some variation in the composition of the primary side chain.

This illustrates that the eugenol analogues have been tested several times before over the last century and found to have some attractiveness for other species. While it shows that when lures are tested against one or two species, the information gained only pertains to those species, when considered in conjunction with the results of this study, it also demonstrates that lures found to be weakly attractive to some species may have a strong attractiveness for others.

Fay (2010) tested these lures at one site in north Queensland for a few months and generally reported a more limited range of species than found in this study, which highlights the value of field testing widely in a range of habitats. However, he did record responses not found in this study. He recorded $B$. jarvisi as weakly attracted to dihydroeugenol and $B$. nigrovittata, a non-responsive species previously only known from PNG, responding to methyl-isoeugenol. The latter species was not trapped during this study. Fay (2010) also dosed the wicks at a lower rate of $2 \mathrm{~mL}$ lure $: 1 \mathrm{~mL}$ maldison or dichlorvos, whereas in this study $3 \mathrm{~mL}$ lure : $1 \mathrm{~mL}$ maldison was used. The combination of lower lure ratio and different insecticides may also have affected trap catch.

\section{3 carbon primary side chain}

Isoeugenol, methyl-isoeugenol, dihydroeugenol and ME all have three-carbon primary side chains (Table 3) and were all effective attractants. However, other compounds with a threecarbon primary side chain were tested in this study, or previously by others, and found to be less attractive.

The only compound with an allyl primary side chain that was attractive to fruit flies in this study was ME. No flies were caught at other allyl-bearing compounds 4-allylanisole or eugenyl acetate and a single $D$. pusillus only was trapped at eugenol (Table 3). This ME-responsive species is only occasionally recorded at ME (JE Royer unpubl. data 2014) and only five single flies were trapped at ME during this study. Fay (2010) found eugenol weakly attractive to $B$. visenda. Howlett (1915) also tested eugenol and only caught a single male of 'an entirely fresh species that exhibited the characteristic beglamoured behaviour and had all the appearance of having found its own particular bait'. Fay (2010) found another compound 4-allylphenol weakly attractive to $B$. sp. nr. quadrata 
(a possibly new species similar to $B$. mayi), although no flies were reportedly trapped at 4-allyl-2,6-dimethoxyphenol, which has substituents in the ortho, para and meta positions.

The only compound tested with a propyl primary substituent was dihydroeugenol (Table 3). DeMilo et al. (1994) tested similar propyl compounds and found 1,2-dimethoxy-4propylbenzene and 4-propyl-2-ethoxy-1-methoxybenzene to have good persistency and to be relatively attractive to B. dorsalis. 1,2-dimethoxy-4-propylbenzene has recently been field tested in northern and southern Queensland in the spring of 2014 and has only attracted low numbers of ME-responsive flies B. cacuminata, B. endiandrae, B. musae and B. sp. nr. quadrata (JE Royer unpubl. data 2014).

Attractive propenyl compounds tested were isoeugenol and methyl-isoeugenol while isoeugenyl acetate caught no flies (Table 3). Fay (2010) tested anethole (methoxy para) and did not report trapping any flies.

DeMilo et al. (1994) systematically tested dialkoxybenzenes (methyl and/or ethyl substituted at the para and meta positions) with varying length primary carbon chains for attractiveness against $B$. dorsalis. They found that three carbon chains (propyl, propenyl and allyl) at the primary position were the most attractive with good persistence after 7 days. Two carbon chain compounds (ethyl) showed good initial attractiveness but decayed quickly and lost all attractiveness after day 3. Metcalf et al. (1983) tested 46 compounds against B. cucurbitae and B. dorsalis and found that for $B$. dorsalis the optimum size for the primary side chain is 3-atomic diameters.

\section{Response to zingerone}

This lure attracted two new undescribed species on Cape York Peninsula: D. sp. nr. pusillus and one specimen of another Dacus. These new species will be described in another paper (JE Royer \& DL Hancock unpubl. data 2014). The ME-responsive D. pusillus and D. sp. nr. pusillus are both known from the Lockhart River region with the former species also known from various locations between the Torres Strait islands and Ingham (Drew 1989; Drew et al. 1999; Royer \& Hancock 2012).

Zingerone attracted several other species of Dacus including two cue-responsive species (D. absonifacies and D. secamoneae), which were more responsive to zingerone than cue-lure, and weakly attracted $D$. aequalis, D. axanus and D. bellulus. Dacus are known generally to be cue responders (Metcalf \& Metcalf 1992). With the similarity of zingerone to the cue-lure group and the response of Dacus in this study to zingerone, it would be worthwhile testing this lure in Africa, where there are at least 195 species of Dacus with 36 responding to cue-lure, one responding to Vertlure and the remainder with an unknown response (Hancock 1985b; White 2006; White \& Goodger 2009).

Testing zingerone more widely led to recording new distributions for several species: B. aglaiae, B. aurea, B. speewahensis, D. absonifacies and D. secamoneae in addition to the discovery of two new species of Dacus.
Tan and Nishida (2000) identified zingerone as the compound attracting fruit flies in Bulbophyllum patens orchids that had potential to attract a range of fruit flies. In Malaysia, it attracted ME-responsive (B. carambolae, B. dorsalis, $B$. indonesiae and $B$. umbrosa) and cue-responsive species (B. albistrigata, B. caudata, B. cucurbitae and B. tau) (Tan \& Nishida 2000, 2007). However, no ME-responsive flies were recorded at this lure in Australia in this study or by Fay (2010, 2011).

\section{2-butanone primary side chain}

Zingerone has 2-butanone as the primary substituent as does the highly attractive cue-lure group (cue-lure, raspberry ketone and RKF). Other 2-butanone compounds were tested in this study, or previously by other researchers, and found to be less attractive. Anisylacetone (4-(4 methoxyphenol)-2 butanone) was weakly attractive to three cue-responsive flies (B. alyxiae, $B$. frauenfeldi and B. neohumeralis). This lure is very similar in structure to raspberry ketone but with a methoxy in the para position instead of a hydroxy (Table 3). Fay (2010) found this lure weakly attractive to the cue-responsive B. breviaculeus and B. tryoni. Before cue-lure was discovered, anisylacetone was identified as an attractant for B. cucurbitae (Barthel et al. 1957) but Alexander et al. (1962) later found cue-lure to be 20 times more attractive and attractive to newly emerged flies, whereas anisylacetone only attracted flies as they reached sexual maturity.

A very similar lure 4-(3,4-dimethoxy phenyl)-2-butanone was tested for several months in early 2012 in the Cairns region and trapped only a few $B$. frauenfeldi, a cue-responsive species (one to four per weekly trap catch). Fay (2010) found this lure to be weakly attractive to $B$. jarvisi, a species attracted to zingerone and weakly to cue-lure. This lure has components of both ME and cue-lure with a dimethoxy para and meta and 2-butanone as the primary substituent, but is probably most similar to zingerone, differing only in having a methoxy para instead of a hydroxy (Table 3). Barthel et al. (1957) found this lure attractive to $B$. dorsalis and noted its similarity to $\mathrm{ME}$, but not attractive to B. cucurbitae despite its similarity to anisylacetone.

Benzyl acetone (no substituents meta or para) had been found by Barthel et al. (1957) to be attractive to B. cucurbitae although inferior to anisylacetone.

Drew (1987) suggested that 2-butanone produced by ripening fruit and bacteria on plant surfaces frequented by $B$. tryoni is a rendezvous stimulant that brings mature males into feeding or oviposition sites for developing females. He proposed that 2-butanone is the primary attractive component in the cue-lure molecule.

\section{Species in lower numbers}

Some species were trapped in reasonably low numbers. For example, the trap catches at the new eugenol analogues were lower than those of pest species at cue-lure. Species caught in low numbers are likely to be less prevalent in the environment 
due to a limited host range with a scarcity of hosts, e.g. $B$. barringtoniae, B. bidentata, B. aberrans (which was only trapped twice at isoeugenol) and $B$. aurea (trapped three times at zingerone in the Lockhart River area). Bactrocera aberrans and B. aurea are only known from single rainforest hosts, Cinnamomum oliveri and Alangium villosum ssp. tomentosum respectively (Hancock et al. 2000), and the limited hosts of B. bidentata and B. barringtoniae have been discussed earlier. Conversely, B. tryoni is frequently trapped in high numbers at cue-lure as it has over 100 hosts that are widespread in north Queensland. Another non-pest species B. cacuminata is trapped in high numbers at $\mathrm{ME}$ as its host is the widespread weed, wild tobacco Solanum mauritianum (Hancock et al. 2000; JE Royer unpubl. data 2014). It is difficult to accurately gauge the degree of attractiveness of lures in field tests without knowing population abundance, though this can be deduced to a degree by taking host abundance into consideration.

Low trap catches can also indicate that a lure is weakly attractive, particularly when there is a stronger lure with which to compare catches. The lower catches of ME-responsive species to the eugenol analogues clearly indicate that these lures are weakly attractive to those species, since much higher numbers were trapped at ME. With the exception of B. yorkensis, the highest relative catches of ME-responsive species were B. pallida at methyl-isoeugenol, which was roughly half that at $\mathrm{ME}$, and $B$. visenda at dihydroeugenol, which was roughly $15 \%$ of that at ME. Field comparison of different lures provides information on their relative attractiveness and confirms suspicions of weakness of attractiveness of some lures for some species, e.g. B. kraussi being weakly attracted to cue-lure as demonstrated by its stronger attraction to isoeugenol. It even leads to unexpected findings such as B. yorkensis, a ME-responsive species, being in fact weakly attracted to ME relative to methyl-isoeugenol, isoeugenol and dihydroeugenol.

\section{Lure chemical structure and Dacini chemoreceptors}

The basic structure of a phenylpropanoid or phenylbutanoid with substituents in the para or para and meta positions appears to be a general structure attractive to Dacini. The generic response by dacine flies to chemicals such as zingerone, cue-lure, ME and Vertlure indicates that their receptors are attuned to this basic structure (Raghu 2004). The new lures found to be attractive in this study also have the phenylpropanoid structure.

Metcalf et al. (1981) concluded that the antennal kairomone receptor of the $B$. dorsalis male is complementary in size and shape to the ME molecule and maximal depolarisation occurs when the receptor is occupied by phenylpropanoids with an aromatic ring attached to a three-atom side chain and substituted in the 3,4-positions with alkoxy groups. Compounds with single ring substituents ortho or meta to the side chain were essentially inactive. This was confirmed by Fay (2010) who tested such compounds with no response.
Metcalf and Metcalf (1992) suggested that small mutational changes in male antennal receptor sites occurred so that these could accommodate the increasing array of lipophilic plant essential oils in the newly evolving angiosperms.

While the phenylpropanoid/phenylbutanoid structure is attractive to many species, recently Nishida and Tan (2014) found that beta-caryophyllene was more attractive to B. correcta (Bezzi) males than ME. This compound is a sesquiterpene of very different chemical structure to the benzene ring compounds and is presumably attaching to a different receptor site.

\section{Methods of discovering lures and value of field testing in areas of high endemicity}

To date, lures have been discovered serendipitously, through mass screening, or through chemical analysis of compounds in plants or rectal pheromone gland volatiles from wild males. There has been little testing of new compounds in areas of high endemicity apart from that conducted when cue-lure and ME were discovered and the recent work in north Queensland and Malaysia (Tan \& Nishida 2000, 2007; Fay 2010, 2011).

Two lures have been discovered serendipitously. Froggatt in 1909 (Drew 1974) \& Howlett (1912) found that male B. dorsalis were attracted to citronella oil and Howlett (1915) later identified the attractive compound as ME. Vertlure, a species-specific lure, was discovered after D. vertebratus was observed being attracted to a locally made cosmetic product in Africa (Hancock 1985a).

Several mass screening studies have led to the discovery of cue-lure and Latilure. Barthel et al. (1957) tested over 1000 compounds as attractants for B. cucurbitae and found that males were attracted to anisylacetone. Alexander et al. (1962) tested over 100 related compounds and found cue-lure far more attractive to this species. Through mass screening of over 4000 compounds, Beroza and Green (1963) confirmed the superiority of cue-lure for B. cucurbitae. Latilure, a lure for B. latifrons, was identified by screening several hundred compounds (Flath et al. 1994).

Zingerone was identified by isolating compounds found in Bulbophyllum orchid flowers that attracted several species of fruit fly (Tan \& Nishida 2000, 2007). Beta-caryophyllene was identified as a superior attractant to B. correcta than ME through analysis of compounds stored in male B. correcta rectal glands (Nishida \& Tan 2014).

While these methods have led to the discovery of effective male attractants for particular species, this study shows the value in field-testing new compounds in areas of high fruit fly diversity, particularly with compounds found to be weakly attractive to other species or compounds structurally similar to such lures.

\section{The value of weak lure records and 'Iure anomalies'}

Weak or sporadic lure attractions and records considered contamination or incorrect lure records should be examined more 
closely as valuable clues to a structurally similar compound that may be the lure for another species. Bactrocera barringtoniae and B. bidentata had previously been recorded sporadically at ME (Royer \& Hancock 2012; JE Royer unpubl. data 2014), while B. yorkensis was originally (Drew et al. 1999) but subsequently only occasionally (JE Royer unpubl. data 2014) collected at ME. In this study, these species were found to be regularly attracted to compounds structurally similar to ME: methyl-isoeugenol, isoeugenol and dihydroeugenol. Other infrequently trapped cue-responsive species were found to be more attracted to other, structurally similar lures: $D$. absonifacies and $D$. secamoneae to zingerone and B. kraussi to isoeugenol. Bactrocera jarvisi was previously recorded as weakly attracted to cue-lure (Drew 1989) and the structurally similar zingerone was found to be a strong attractant for it (Fay 2011). It is possible that other species elsewhere in the world with a known response to cue-lure or $\mathrm{ME}$ are actually more strongly attracted to another as yet unidentified lure.

A weak lure response from one species might indicate that it is a strong attractant for another species in a different geographic region. Isoeugenol was found to attract $B$. diversa in India (Howlett 1915) and B. dorsalis and B. latifrons in Hawaii (Steiner 1952; Flath et al. 1994) and it has proven to be an effective attractant for B. kraussi and B. halfordiae in Australia. Zingerone weakly attracted cue- and ME-responsive species in Malaysia (Tan \& Nishida 2000, 2007) but was a highly effective attractant for B. jarvisi in Australia (Fay 2011).

It is apparent from this study that many fruit fly species in Australia respond to several lures but with a much stronger response to one particular lure. This confirms findings in past studies for B. dorsalis, B. cucurbitae and B. latifrons (e.g. Alexander et al. 1962, Beroza \& Green 1963, Metcalf \& Metcalf 1992, DeMilo et al. 1994, Flath et al. 1994). That a species responds to several lures with a stronger response to one lure has been known since the first discovery of a fruit fly lure by Howlett (1912). He commented that 'we might look on each species as tuned to respond to three or four notes on the scale of smell, and we should expect to find the most delicate adjustment and most accurate tuning in the direction of the sexual smell, since errors of perception would here be most disadvantageous to the species'.

The lures studied here in Queensland have also been field tested in Bhutan in an area infested with B. minax, a nonresponsive pest of citrus in Asia. There was no catch of this species with any of the lures tested (JE Royer \& K Mahat unpubl. data 2014). However, B. minax has previously been trapped at ME, but only over a very short time period in spring, which was correlated with the fly's sexual maturation and mating (AR Clarke unpubl. data 2014). Field testing of these lures in PNG was also conducted in 2012-2013 and found to attract non-responsive species; this will be reported in another paper (JE Royer et al. unpubl. data 2014).

In summary, this study found (1) a male lure for B. halfordiae, a potential market access pest; (2) improved male lures for several species of some economic concern
Table 6 Lures found to be most attractive for fruit fly species previously recorded as non-responsive, cue- or ME-responsive

\begin{tabular}{|c|c|c|}
\hline Species & $\begin{array}{c}\text { Previous recorded lure } \\
\text { response }\end{array}$ & $\begin{array}{c}\text { Most attractive } \\
\text { lure }\end{array}$ \\
\hline B. aeroginosa & Cue-lure & RKF \\
\hline B. barringtoniae & Non-responsive & Methyl-isoeugenol \\
\hline B. bidentata & Non-responsive & $\begin{array}{l}\text { Dihydroeugenol \& } \\
\text { isoeugenol }\end{array}$ \\
\hline B. bryoniae ${ }^{\dagger}$ & Cue-lure & RKF \\
\hline B. frauenfeld $i^{\dagger}$ & Cue-lure & RKF \\
\hline B. halfordiae $e^{\ddagger}$ & Non-responsive & Isoeugenol \\
\hline B. kraussi ${ }^{\dagger}$ & Cue-lure & Isoeugenol \\
\hline B. manskii & Cue-lure & RKF \\
\hline B. murrayi & Non-responsive, isoeugenol & Methyl-isoeugenol \\
\hline B. silvicola & Cue-lure & RKF \\
\hline B. tryoni $i^{\dagger}$ & Cue-lure & RKF \\
\hline B. yorkensis & $\mathrm{ME}$ & Methyl-isoeugenol \\
\hline D. absonifacies & Cue-lure & Zingerone \\
\hline D. secamoneae & Cue-lure & Zingerone \\
\hline
\end{tabular}

${ }^{\dagger}$ Species of some economic importance.

${ }^{\ddagger}$ Species of market access concern due to old host records (May 1953).

(isoeugenol for B. kraussi, RKF for B. tryoni, B. frauenfeldi and B. bryoniae); (3) discovered two new species of Dacus at zingerone; (4) recorded significant new distributions for five Bactrocera and two Dacus species; (5) recorded two cueresponsive species of Dacus as more attracted to zingerone; and (6) one ME-responsive Bactrocera species as more attracted to the eugenol analogues (Table 6). This work highlights the value of testing new compounds in areas of high species diversity, particularly with compounds structurally similar to lures that have weakly attracted species or compounds found to have some attractiveness for other species.

\section{ACKNOWLEDGEMENTS}

This research was funded by the Australian Centre for International Agricultural Research under the project PC2012/053 Feasibility study on novel lures for pest fruit flies that do not respond to known male attractants.

I would like to thank Dr Harry Fay for providing the impetus for this project, Dr David Mayer for statistical analysis of the data, Rose Laughton and Linda Baker for field work and assistance with identification of fruit flies, John Pritchard, Jack and Sue Hasenpusch for trapping conducted at Lockhart River and Garradunga, Drs David Hancock, Andrew Hayes and Roger Shivas for comment on the manuscript, Dr Andrew Hayes for assistance with chemical structure drawings, the Men's Shed Cairns for making Steiner traps and CSIRO Atherton for allowing traps to be set at their research station.

\section{REFERENCES}

Alexander BH, Beroza B, Oda TA, Steiner LF, Miyashita DH \& Mitchell WC. 1962. The development of male melon fly attractants. Journal of Agriculture \& Food Chemistry 10, 270-276. 
Barthel WF, Green N, Keiser I \& Steiner LF. 1957. Anisylacetone, synthetic attractant for male melon fly. Science 126, 654.

Beroza M \& Green N 1963. Materials tested as insect attractants. Agriculture Handbook No. 239. Agriculture Service, United States Department of Agriculture.

Beroza M, Alexander BH, Steiner LF, Mitchell WC \& Miyashita DH. 1960. New synthetic lures for the male melon fly. Science 131, 10441045.

Casana-Giner V, Oliver JE, Jang EB \& Carvalho LA. 2003a. Syntheses and behavioral evaluations of fluorinated and silylated analogs of raspberry ketone as attractants for melon fly, Bactrocera cucurbitae (Coquillett). Journal of Entomological Science 38, 111-119.

Casana-Giner V, Oliver JE, Jang EB et al. 2003b. Raspberry ketone formate as an attractant for the melon fly (Diptera: Tephritidae). Journal of Entomological Science 38, 120-126.

DeMilo AB, Cunningham RT \& McGovern TP. 1994. Structural variants of methyl eugenol and their attractiveness to the Oriental fruit fly (Diptera: Tephritidae). Journal of Economic Entomology 87, 957964.

Drew RAI. 1974. The responses of fruit fly species (Diptera: Tephritidae) in the South Pacific area to male attractants. Journal of the Australian Entomological Society 13, 267-270.

Drew RAI. 1987. Behavioural strategies of fruit flies of the genus Dacus (Diptera: Tephritidae) significant in Mating and host-plant relationships. Bulletin of Entomological Research 77, 73-81.

Drew RAI. 1989. The tropical fruit flies (Diptera: Tephritidae: Dacinae) of the Australasian and Oceanian Regions. Memoirs of the Queensland Museum 26, 1-521.

Drew RAI \& Romig MC. 2013. Tropical Fruit Flies (Tephritidae: Dacinae) of South-East Asia. CAB International, Wallingford, UK.

Drew RAI, Hooper GHS \& Bateman MA. 1982. Economic Fruit Flies of the South Pacific Region, 2nd edn., Queensland Department of Primary Industries, Brisbane, Australia.

Drew RAI, Hancock DL \& Romig MC. 1999. New species and records of fruit flies (Diptera: Tephritidae: Dacinae) from north Queensland. Australian Entomologist 26, 1-12.

Enomoto H, Ishida T, Hamagami A \& Nishida R. 2010. 3-Oxygenated a-ionone derivatives as potent male attractants for the solanaceous fruit fly, Bactrocera latifrons (Diptera: Tephritidae), and sequestered metabolites in the rectal gland. Applied Entomology and Zoology 45, $551-556$.

Fay HAC 2010. Exploring structure-activity relationships in the phenylpropanoids to procure new male lures for non-responsive Bactrocera and Dacus. Proceedings of the $8^{\text {th }}$ International Symposium on Fruit Flies of Economic Importance, Valencia, 270-280.

Fay HAC. 2011. A highly effective and selective male lure for Bactrocera jarvisi (Tryon) (Diptera: Tephritidae). Australian Journal of Entomology 51, 189-197.

Flath RA, Cunningham RT, Liquido NJ \& McGovern TP. 1994. Alphaionol as attractant for trapping Bacrocera latifrons (Diptera: Tephritidae). Journal of Economic Entomology 87, 1470-1476.

GenStat. 2013. GenStat for Windows, Release 15.3. VSN International Ltd., Oxford.

Hancock DL. 1985a. A specific male attractant for the melon fly Dacus vertebratus. Zimbabwe Science News 19, 118-119.

Hancock DL. 1985b. New species and records of African Dacinae (Diptera: Tephritidae). Arnoldia Zimbabwe 9, 299-314.

Hancock DL. 2013. A revised checklist of Australian fruit flies (Diptera: Tephritidae). Australian Entomologist 40, 219-236.

Hancock DL, Hamacek EL, Lloyd AC \& Elson-Harris MM. 2000. The Distribution and Host Plants of Fruit Flies (Diptera: Tephritidae) in Australia. Queensland Department of Primary Industries, Brisbane, Australia. Information Series Q199067.

Hee AKW \& Tan KH. 1998. Attraction of female and male Bacrocera papayae to conspecific males fed with methyl eugenol and attraction of females to male sex pheromone components. Journal of Chemical Ecology 24, 753-764.

Hee AKW \& Tan KH. 2005. Bioactive fractions containing methyl eugenol-derived sex pheromonal components in haemolymph of the male fruit fly Bactrocera dorsalis (Diptera: Tephritidae). Bulletin of Entomological Research 95, 615-620.
Hee AKW \& Tan KH. 2006. Transport of methyl eugenol-derived sex pheromonal components in the male fruit fly Bactrocera dorsalis. Comparative Biochemistry and Physiology Part C: Toxicology \& Pharmacology 143, 422-428.

Howlett FM. 1912. The effect of oil of citronella on two species of Dacus. Transactions of the Royal Entomological Society of London 2, 412418.

Howlett FM. 1915. Chemical reactions of fruit flies. Bulletin of Entomological Research 6, 297-305.

Huxham KA \& Hancock DL. 2002. New records of Dacinae (Diptera: Tephritidae) from northern Queensland and Torres Strait, Australia. Australian Entomologist 29, 123-126.

Huxham KA, Fay HAC \& Hancock DL. 2006. Two new species and a new Australian record of Bactrocera Macquart (Diptera: Tephritidae: Dacinae) from northern Queensland, Torres Strait and Papua New Guinea. Australian Journal of Entomology 45, 34-37.

IAEA. 2003. Trapping guidelines for area-wide fruit fly programmes. Joint FAO/IAEA Division of Nuclear Techniques in Food and Agriculture, International Atomic Energy Agency, Vienna.

Ishida T, Entomoto H \& Nishida R. 2008. New attractants for males of the solanaceous fruit fly Bactrocera latifrons. Journal of Chemical Ecology 34, 1532-1535.

Jang EB, Casana-Giner V \& Oliver JE. 2007. Field captures of wild melon fly (Diptera: Tephritidae) with an improved male attractant, raspberry ketone formate. Journal of Economic Entomology 100, $1124-1128$.

Jang EB, Khrimian A \& Siderhurst MS. 2011. Di- and tri- fluorinated analogs of methyl eugenol: attraction to and metabolism in the Oriental fruit fly Bactrocera dorsalis (Hendel). Journal of Chemical Ecology 37, 553-564.

Khrimian A, Jang EB, Nagata J \& Carvalho L. 2006. Consumption and metabolism of 1,2-dimethoxy-4-(3-fluoro-2-propenyl)benzene, a fluorine analog of methyl eugenol, in the Oriental fruit fly Bactrocera dorsalis (Hendel). Journal of Chemical Ecology 32, 1513-1526.

Khrimian A, Siderhurst MS, McQuate GT et al. 2009. Ring-fluorinated analog of methyl eugenol: attractiveness to and metabolism in the Oriental fruit fly, Bactrocera dorsalis (Hendel). Journal of Chemical Ecology 35, 209-218.

Kumaran N, Balagawi S, Schutze MK \& Clarke AR. 2013. Evolution of lure response in tephritid fruit flies: phytochemicals as drivers of sexual selection. Animal Behaviour 85, 781-789.

Kumaran N, Hayes RA \& Clarke AR. 2014. Cuelure but not zingerone make the sex pheromone of male Bactrocera tryoni (Diptera: Tephritidae) more attractive to females. Journal of Insect Physiology 68, 36-43.

Liquido NJ, Khrimian AP, DeMilo AB \& McQuate GT. 1998. Monofluoro analogues of methyl eugenol: new attractants for males of Bactrocera dorsalis (Hendel) (Dipt. Tephritidae). Journal of Applied Entomology 122, 259-264.

McCullagh P \& Nelder JA. 1989. Generalized Linear Models, 2nd edn., Chapman and Hall, London.

McGovern TP, Flath RA \& Cunningham RT 1989. Attractants for Dacus latifrons, the Malaysian fruit fly. United States Patent Number 4877607.

McQuate GT \& Peck SL. 2001. Enhancement of attraction of alpha ionol to male Bactrocera latifrons (Diptera: Tephritidae) by addition of a synergist cade oil. Journal of Economic Entomology $\mathbf{9 4}$, 39-46.

McQuate GT, Keum YS, Sylva CD, Li QX \& Jang EB. 2004. Active ingredients in cade oil that synergise attractiveness of alpha-ionol to male Bactrocera latifrons (Diptera: Tephritidae). Journal of Economic Entomology 97, 862-870.

May AWS. 1953. Queensland host records for the Dacinae (fam. Trypetidae). First supplementary lists. Queensland Journal of Agricultural Science 14, 29-39.

Meats A \& Hartland CL. 1999. Upwind anemotaxis in response to cuelure by the Queensland fruit fly, Bactrocera tryoni. Physiological Entomology 24, 90-97.

Metcalf RL. 1990. Chemical ecology of Dacinae fruit flies (Diptera: Tephritidae). Annals of the Entomological Society of America 83, 1017-1030. 
Metcalf RL \& Metcalf RE. 1992. Plant Kairomones in Insect Ecology and Control. Chapman and Hall, New York, USA.

Metcalf RL, Mitchell WC, Fukuto TR \& Metcalf ER. 1975. Attraction of Oriental fruit fly Dacus dorsalis to methyl eugenol and related olfactory stimulants. Proceedings of the National Academy of Science of the United States of America 72, 2501-2505.

Metcalf RL, Metcalf ER \& Mitchell WC. 1981. Molecular parameters and olfaction in the oriental fruit fly Dacus dorsalis. Proceedings of the National Academy of Science of the United States of America 78, 4007-4010.

Metcalf RL, Mitchell WC \& Metcalf ER. 1983. Olfactory receptors in the melon fly Dacus cucurbitae and the oriental fruit fly Dacus dorsalis. Proceedings of the National Academy of Science of the United States of America 80, 3143-3147.

Metcalf RL, Metcalf ER \& Mitchell WC. 1986. Benzyl acetates as attractants for the male oriental fruit fly, Dacus dorsalis, and the male melon fly, Dacus cucurbitae. Proceedings of the National Academy of Science of the United States of America 83, 1549-1553.

Mitchell WC, Metcalf RL, Metcalf ER \& Mitchell S. 1985. Candidate substitutes for methyl eugenol as attractants for the area-wide monitoring and control of the Oriental fruit fly, Dacus dorsalis Hendel (Diptera: Tephritidae). Environmental Entomology 14, 176-181.

Nishida R \& Tan KH 2014. Search for new fruit fly attractants from plants. $9^{\text {th }}$ International Symposium on Fruit Flies of Economic Importance. Bangkok, Thailand.

Oliver JE, Casana-Giner V, Jang EB, McQuate GT \& Carvalho L 2002. Improved attractants for the melon fly, Bactrocera cucurbitae. Proceedings of the $6^{\text {th }}$ International Fruit Fly Symposium, South Africa, 283-290.

Raghu S. 2004. Functional significance of phytochemical lures to dacine fruit flies (Diptera: Tephritidae): an ecological and evolutionary synthesis. Bulletin of Entomological Research 94, 385-399.

Royer JE \& Hancock DL. 2012. New distribution and lure records of Dacinae (Diptera: Tephritidae) from Queensland, Australia, and a description of a new species of Dacus Fabricius. Australian Journal of Entomology 51, 239-247.

Shelly TE. 2000. Fecundity of female oriental fruit flies (Diptera: Tephritidae): effects of methyl eugenol-fed and multiple mates. Annals of the Entomological Society of America 93, 559-564.

Shelly TE \& Dewire AM. 1994. Chemically mediated mating success in male oriental fruit flies (Diptera: Tephritidae). Annals of the Entomological Society of America 87, 375-382.

Steiner LF. 1952. Methyl eugenol as an attractant for the oriental fruit fly. Journal of Economic Entomology 45, 241-248.

Tan KH 2006. Fruit fly pests as pollinators of wild orchids. Proceedings of the $7^{\text {th }}$ International Symposium on Fruit Flies of Economic Importance, Brazil, 195-206.
Tan KH \& Nishida R. 1996. Sex pheromone and mating competition after methyl eugenol consumption in the Bactrocera dorsalis complex. In: Fruit Fly Pests (eds BA McPheron \& GJ Steck), pp. 147-153. St Lucie Press, Boca Raton, USA.

Tan KH \& Nishida R. 2000. Mutual reproductive benefits between a wild orchid, Bulbophyllum patens, and Bactrocera fruit flies via a floral synomone. Journal of Chemical Ecology 26, 533-546.

Tan KH \& Nishida R. 2007. Zingerone in the floral synomone of Bulbophyllum baileyi (Orchidaceae) attracts Bactrocera fruit flies during pollination. Biochemical Systematics and Ecology 35, 334341.

Tan KH \& Nishida R. 2012. Methyl eugenol: its occurrence, distribution, and role in nature, especially in relation to insect behaviour and pollination. Journal of Insect Science [electronic source] 12, 1-74.

Tan KH, Nishida R \& Toong YC. 2002. Floral synomone of a wild orchid, Bulbophyllum cheiri, lures Bactrocera fruit flies for pollination. Journal of Chemical Ecology 28, 1161-1172.

Tan KH, Tan LT \& Nishida R. 2006. Floral phenylpropanoid cocktail and architecture of Bulbophyllum vinaceum orchid in attracting fruit flies for pollination. Journal of Chemical Ecology 32, 24292441.

Tan KH, Tokushima I, Ono H \& Nishida R. 2011. Comparison of phenylpropanoid volatiles in male rectal pheromone gland after methyl eugenol consumption, and molecular phylogenetic relationship of four global pest fruit fly species: Bactrocera invadens, $B$. dorsalis, B. correcta and B. zonata. Chemoecology 21, 25-33.

Wee SL \& Tan KH. 2007. Temporal accumulation of phenylpropanoids in male fruit flies Bactrocera dorsalis and B. carambolae (Diptera: Tephritidae) following methyl eugenol consumption. Chemoecology 17, 81-85.

Wee SL, Tan KH \& Nishida R. 2007. Pharmacophagy of methyl eugenol by males enhances sexual selection of Bactrocera carambolae. Journal of Chemical Ecology 33, 1272-1282.

White IM. 2001. Morphological features of the tribe Dacini (Dacinae): their significance to behavior and classification. In: Fruit Flies (Tephritidae): Phylogeny and Evolution of Behavior (eds M Aluja \& AL Norrbom), pp. 505-534. CRC Press, Boca Raton, USA.

White IM. 2006. Taxonomy of the Dacina (Diptera: Tephritidae) of Africa and the Middle East. African Entomology Memoir 2, 1-156.

White IM \& Elson-Harris MM. 1992. Fruit Flies of Economic Significance: Their Identification and Bionomics. CAB International, London, UK.

White IM \& Goodger KFM. 2009. African Dacus (Diptera: Tephritidae); new species and data, with particular reference to the Tel Aviv University collection. Zootaxa 2127, 1-49.

Accepted for publication 17 December 2014. 